\title{
Significant Differences in the Prevalence of Elevated HbA1c Levels for Type I and Type II Diabetics Attending the Parirenyatwa Diabetic Clinic in Harare, Zimbabwe
}

\author{
Kurai Z. Chako, ${ }^{1}$ Heather Phillipo, ${ }^{1}$ Erisi Mafuratidze, ${ }^{1}$ and Danai Tavonga Zhou ${ }^{1,2}$ \\ ${ }^{1}$ Department of Medical Laboratory Sciences, University of Zimbabwe College of Health Sciences, P.O. Box AV 178, \\ Avondale, Harare, Zimbabwe \\ ${ }^{2}$ Faculty of Medicine, University of Oslo, P.O. Box 1078, Blinden, 0316 Oslo, Norway
}

Correspondence should be addressed to Danai Tavonga Zhou; danaizh@yahoo.co.uk

Received 14 October 2013; Accepted 21 November 2013; Published 23 January 2014

Academic Editors: A. Castañeyra-Perdomo, W. Ding, and J. Xie

Copyright (C) 2014 Kurai Z. Chako et al. This is an open access article distributed under the Creative Commons Attribution License, which permits unrestricted use, distribution, and reproduction in any medium, provided the original work is properly cited.

\begin{abstract}
Diabetics have chronically elevated glucose levels. High levels of glucose result in nonenzymatic formation of glycosylated haemoglobin (HbAlc). Therefore, elevated HbAlc is a good indicator of poorly controlled diabetes. We used the standard HbAlc method to determine glycemic control in diabetics attending a public health facility in Harare, Zimbabwe. Our study sought to assess the prevalence of elevated HbAlc amongst treated diabetics and compare the HbAlc levels by type of diabetes. The crosssectional study was carried out at one of the main public health centres in Zimbabwe: the Parirenyatwa Group of Hospitals in Harare. Type I and type II diabetics were recruited and had their blood HbAlc levels measured. The standard one tailed proportion $z$ test was used to test the hypothesis at 5\% significance level. Combined prevalence of type I and type II diabetics with elevated HbAlc was $27 \%$. There was no significant difference in levels of HbAlc by age and sex. Over half (54\%) of Type I diabetics had elevated HbAlc, suggesting poor glycemic control. In contrast only $24 \%$ of the Type II diabetics studied had elevated HbAlc. The difference in proportion of Type I and Type II diabetics with elevated HbAlc suggestive of poor glycemic control was significant $(P=0.0067)$.
\end{abstract}

\section{Introduction}

According to the World Health Organization (WHO) diabetes mellitus is a state of chronic hyperglycaemia due to genetic and environmental factors. In Type 1 diabetes mellitus there is no production of insulin whereas in Type 2 diabetes mellitus there is insufficient insulin or cells do not respond to insulin present in the body (insulin resistance). The most frequent form is Type 2 diabetes ( $80 \%$ of cases) whilst Type 1 diabetes accounts for $10 \%$ of cases and specific diabetes such as gestational diabetes accounts for $5 \%$ of cases $[1,2]$.

In 2004 it was estimated that up to 3.4 million people died from diabetes and $80 \%$ of these deaths occurred in low and middle income countries such as Zimbabwe [35]. Half of the people who died as a result of diabetes were under the age of $70,55 \%$ of them women [3-5]. Diabetes mellitus was generally considered to be a rare condition in
Africa before the 1990s. Evidence of increased incidence and prevalence of type 2 diabetes mellitus was provided by some epidemiological studies carried out in that decade [5-7]. Africa is experiencing a demographic and epidemiological transition with a rise in diseases like diabetes mellitus. Most reports published between 1959 and 1985 indicated a prevalence of diabetes below $1.4 \%$ with the exception of those from South Africa where higher prevalence was seen [5-7].

Different tests are used in diabetes mellitus patients and these include random and fasting blood glucose, oral glucose tolerance test, blood urea, blood hydrogen, urinary protein, blood insulin, blood fructosamine, and glycosylated haemoglobin (HbAlc) [8]. For diagnosis the oral glucose tolerance test (OGTT), fasting and random blood glucose tests are ideal. According to the WHO guidelines, if the plasma glucose is less than $5.5 \mathrm{mmol} / \mathrm{L}$, then diabetes is highly unlikely [1]. A fasting plasma glucose of $7.0 \mathrm{mmol} / \mathrm{L}$ 
or more or a random glucose of $11.1 \mathrm{mmol} / \mathrm{L}$ or more makes diabetes likely and the diagnosis is confirmed by a repeated abnormal test. If the fasting plasma glucose is between 5.5 and $6.9 \mathrm{mmol} / \mathrm{L}$ or between 5.5 and $11.0 \mathrm{mmol} / \mathrm{L}$ nonfasting an OGTT with $75 \mathrm{~g}$ anhydrous glucose should be done [1]. Blood hydrogen, blood urea, and urinary protein can also be used in diagnosis of diabetes but only as confirmatory tests for fasting, random blood glucose, and OGTT. Blood insulin is rarely measured in diagnosis of diabetes mellitus [1].

In the management and control of diabetes, blood glucose determined at the time of the clinic attendance can only give limited information and may not represent the overall closeness of control at other times. The glycosylated haemoglobin (HbAlc) test provides a better index of diabetic control than plasma glucose since it is not greatly affected by short-term fluctuations in plasma glucose [9]. HbAlc is a form of haemoglobin used primarily to identify the average plasma glucose concentration over prolonged periods of time (three to four months). In the normal 120-day lifespan of the red blood cell glucose molecules combine with haemoglobin forming $\mathrm{HbAlc}$. In individuals with poorly controlled diabetes, increases in the quantities of the HbAlc have been noted. Once a haemoglobin molecule is glycosylated, it remains that way. HbAlc levels within the red blood cell reflect the average level of glucose to which the cell has been exposed during its life cycle $[1,8]$. The American Diabetic Association and National Institute for Health and Clinical Excellence (NICE) both recommend that \%HbAlc should be below 6.5 in nondiabetics and 7\% in diabetics [10, 11].

The HbAlc test mainly measures level of glycemic control in diabetic patients. It has recently been added as a diagnostic test by the World Health Organization (WHO) but the test requires quality assurance and controls [11]. HbAlc recommended that cut-off point for diagnosing diabetes is 6.5\% [11]. Traditionally, measuring HbAlc assesses the effectiveness of therapy by monitoring long term-plasma glucose regulation. Monitoring of glycogenic status is considered a cornerstone of diabetes care and affects how physicians and patients adjust medical therapy as well as behavioural therapy (diet and exercise). It has been shown in a randomised study that when health care providers and patients are informed about the HbAlc results blood glucose control is improved. Simply knowing the results improves glycemic control, either through improved efforts by the patient or by the provider [12-14].

In a study done to determine the relationship of HbAlc levels to hospital admission of patients, it was found that the likelihood of admission increased with higher HbAlc levels. The number of admissions of diabetic patients with HbAlc levels in the range $10.8 \%-18.4 \%$ was higher with 5 481 admissions in a 3-year period compared with 2566 admissions of patients with HbAlc levels in the reference region of $7.7 \%-8.1 \%$ [15]. One other study showed that an average $\mathrm{HbA1c}$ level of $7.2 \%$ resulted in a $76 \%$ reduction in retinopathy, a $60 \%$ reduction in neuropathy, a $50 \%$ reduction in kidney disease, and a 35\% reduction in cardiovascular disease [16]. Another study in the United States of America demonstrated unequivocally that maintaining close to normal blood glucose levels significantly lowers a person's risk of developing complications of diabetes mellitus [17].

A study by Gerstein et al. showed that high HbAlc levels are associated with increased risk of mortality [18] and this was partially explained by the fact that high $\mathrm{HbAlc}$ levels are associated with increased risk of diabetic macrovascular and microvascular complications $[19,20]$. These may contribute to deteriorating kidney function. Anemia has also been suggested to account for increased risk of mortality associated with increased levels of HbAlc. The reference ranges for our study were $<7 \%$ desirable, $7-9 \%$ suboptimal, and $>9 \%$ poor based on literature [18-20].

Public health laboratories in Zimbabwe do not offer the HbAlc assay for diabetic patients. Many patients are from poor socioeconomic background and rely solely on public health facilities as they cannot afford private healthcare facilities. Thus, most Zimbabwean diabetics do not have any form of long-term monitoring of their blood glucose levels and are at a risk of having high levels of $\mathrm{HbAlc}$ without them or their health care providers knowing it. This study seeks to determine the prevalence of elevated HbAlc (a measure of poor glycemic control) in diabetics at Parirenyatwa Group of Hospitals Diabetic Clinic in Harare, Zimbabwe.

\section{Materials and Methods}

An analytical cross-sectional study was done on blood samples of diabetes mellitus patients attending Parirenyatwa Group of Hospitals Diabetic Clinic in Harare, Zimbabwe.

The minimum sample size (202) was calculated as $S=$ $Z^{2} p q / E^{2}$, where $Z=$ test statistic, $E=$ standard error, $p=$ population proportion with desired characteristic, $q=1-p$, and $S=$ minimum sample size:

$$
S=\frac{1.645^{2} \times 0.25 \times 0.75}{0.05^{2}}=202.09 \text {. }
$$

Ethical clearance was given by the joint Parirenyatwa Hospital-University of Zimbabwe Ethics Committee, and permission to carry out the study was granted by the Clinical Director and Diabetics Clinic Staff. No patient names were used and samples were allocated a research number. Samples, results, and data collected were treated with strict confidentiality and were not accessible to unauthorized persons.

Sequential sampling technique was used to recruit diabetics eligible for the study who had come for routine checkup or monitoring at Parirenyatwa Group of Hospitals Diabetic Clinic. Blood samples were collected from eligible consenting diabetic patients. Blood samples in EDTA tubes were later spun in a centrifuge at $3000 \mathrm{rpm}$ for five minutes in the Department of Medical Laboratory Sciences laboratory. The required amount of packed cells ( 25 microlitres) was aspirated into serum pots and samples were stored at $2-8^{\circ} \mathrm{C}$.

Samples were then assayed at the Department of Medical Laboratory Sciences on the Mindray BS 120 Chemistry Analyzer. 500 microlitres of pretreatment solution was added to 25 microlitres of thawed samples and gently mixed with the cells. The samples were left to stand for five minutes after which the samples were loaded into the analyzer for processing. 
TABLE 1: Descriptive measures in study population.

\begin{tabular}{lcc}
\hline & HbAlc (\%) & Age (years) \\
\hline Mean & 7.5 & 54 \\
Median & 6.8 & 55 \\
S.D & 2.92 & 14.21 \\
Q1 & 5.2 & 44 \\
Q2 & 9.5 & 64 \\
Inter-Quartile Range & 4.3 & 20 \\
Range & $3.4-16.7$ & $19-80$ \\
\hline
\end{tabular}

TABLE 2: Reference range levels of long-term glucose control used in the study.

\begin{tabular}{lccc}
\hline $\begin{array}{l}\text { Level of long-term } \\
\text { glucose control }\end{array}$ & Optimal & Suboptimal & Poor \\
\hline HbAlc level & Desirable & Reasonable & Elevated \\
HbAlc percentage & $<7 \%$ & $7-9 \%$ & $>9 \%$ \\
\hline
\end{tabular}

An enzymatic method was used to determine the levels of $\mathrm{HbAlc}$ in the blood samples. In the first reaction the concentration of haemoglobin is measured at absorbance of fixed wavelength. In a second reaction, fructosyl dipeptides are generated from the $\mathrm{N}$-terminus amino groups of the beta chain of HbAlc by the reaction of protease enzyme. The fructosyl dipeptides react with fructosyl peptide oxidize (FPOX) to generate hydrogen peroxide. Hydrogen peroxide formed reacts with 10-(carboxymethylaminocarbonyl)-3,7bis (dimethylamino) phenothiazine sodium salt to develop a colour in the presence of peroxidase. The change in absorbance is measured for HbAlc determination. The combined assay results (haemoglobin and $\mathrm{HbAlc}$ ) are used by the system to calculate and express percentage $\mathrm{HbAlc}$.

The standard one tailed proportion $z$ test was used to test the hypothesis at $5 \%$ significance level.

\section{Results and Analysis}

A total of 290 diabetics (117 men and 173 women) who attended Parirenyatwa Diabetic Clinic during the time of study had their samples analysed for HbAlc. Twelve percent $(N=35)$ of the patients studied were type 1 and 255 were type 2 diabetics. Mean age (IQR) was 54 years (20), whilst mean $\%$ HbAlc (IQR) was 7.5\% (4.3) (Table 1).

HbAlc levels and age did not follow a normal distribution ( $P=0.0$ for HbAlc and $P=0.00195$ for age) both calculated using the Shapiro-Wilk test for normal distribution.

The level of glucose control was defined using \% HbAlc as shown in Table 2.

The distribution of glycemic control was optimal for $55 \%$ of the diabetics, whist $45 \%$ did not have good glycemic control (Figure 1).

Level of glycemic control was also compared by age group of patients (Table 3). There was no statistically significant difference in distribution of glycemic control among the three age categories, $P=0.9790$.

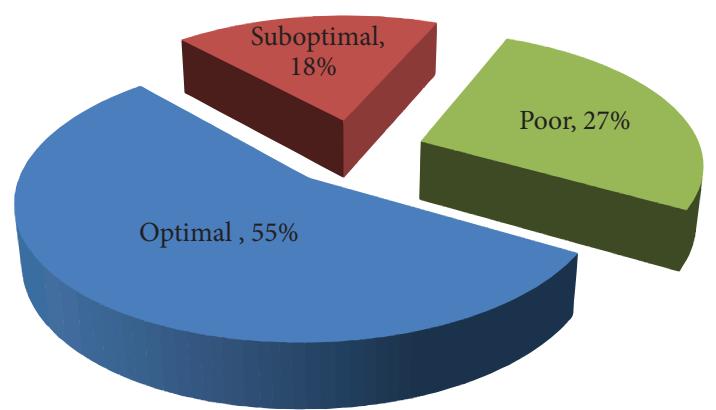

FIGURE 1: Distribution of levels of glycemic control in the study population.

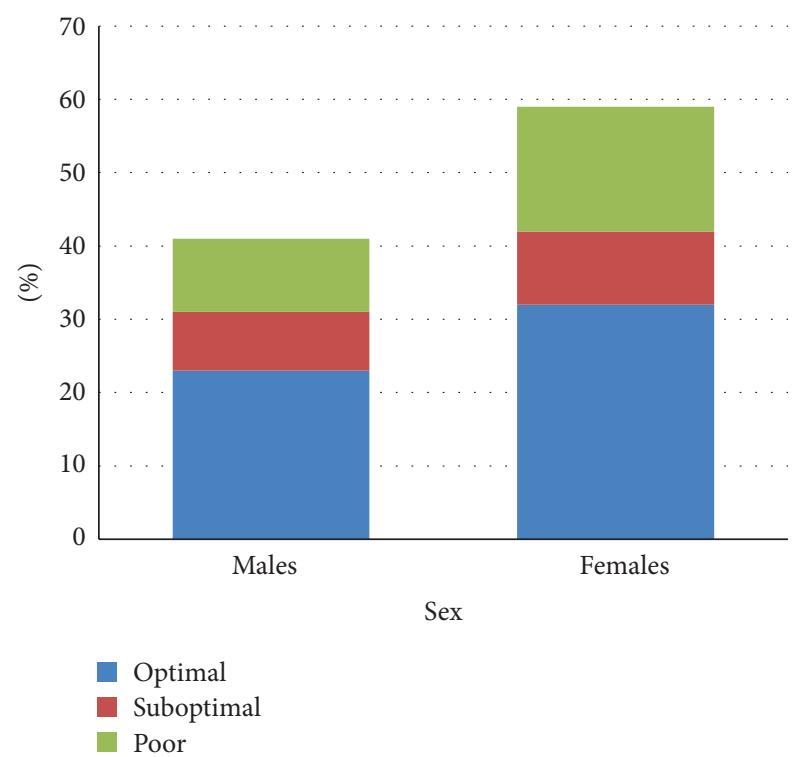

FIGURE 2: Distribution of glycemic control levels by sex in the study population.

The distribution of glycemic control between males and females was compared (Figure 2). Using the Wilcoxon rank sum (Mann-Whitney) method, there was no statistically significant difference in glycemic control between the two sexes, $P=0.7537$.

Figure 3 shows a comparison of the levels of glycemic control by type of diabetes. There was a statistically significant difference in glycemic control of study participants by types of diabetes mellitus, $P=0.00867$.

\section{Discussion}

In a diet control study of diabetics with $\mathrm{HbAlc}$ results available, in the United States, it was shown that 39\% had good control (HbAlc < 7\%), 36\% had suboptimal control (HbAlc 7-9\%), and 25\% had poor control (HbAlc > 9\%) [21] . Our data indicated that the prevalence of elevated HbAlc levels (27\%) among diabetics attending the Parirenyatwa Diabetic Clinic in Zimbabwe was greater than the proportion of $25 \%$ found in the American study, $z$-score $=1.665$ [21] . This contradicts the epidemiological studies showing that 
TABLE 3: Levels of glycemic control in different age groups of study population.

\begin{tabular}{lcccc}
\hline \multirow{2}{*}{ Age Group } & Optimal control & Suboptimal control & Poor control & \multicolumn{2}{c}{ Total participants } \\
& $N(\%)$ & $N(\%)$ & $N(\%)$ & 47 \\
\hline $18-40$ & 33 & 3 & $(24)$ & $(100)$ \\
years & $(70)$ & $(6)$ & 32 & 1122 \\
$41-60$ & 68 & 22 & $(26)$ & $(100)$ \\
years & $(56)$ & 28 & 34 & 121 \\
$61-80$ & 59 & $(23)$ & $(28)$ & $(100)$ \\
years & $(49)$ & & & \\
\hline
\end{tabular}

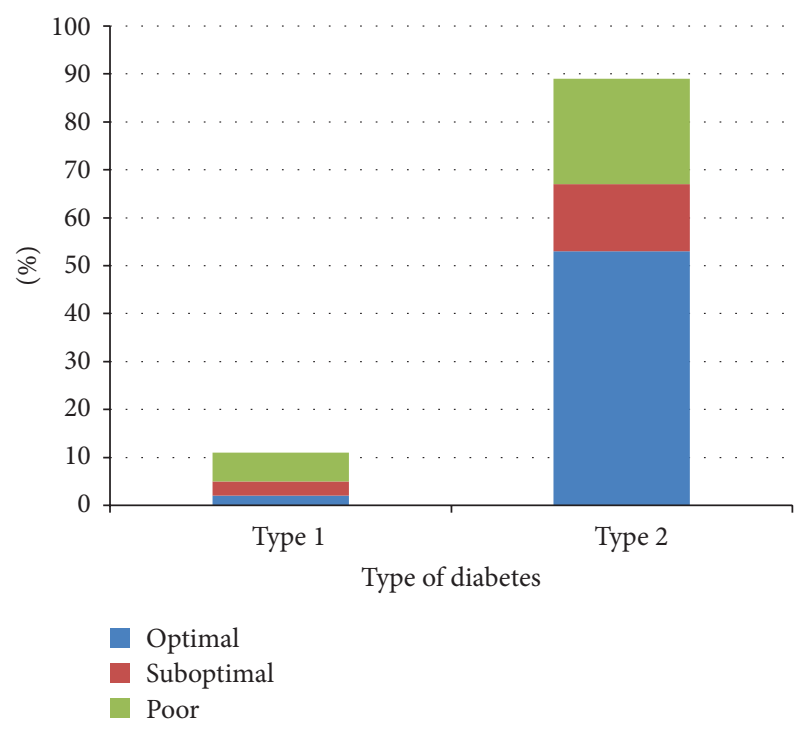

FIGURE 3: Distribution of levels of glycemic control in type 1 and 2 diabetics in the study population.

diabetes mellitus has a higher prevalence in developed than in developing countries [4, 22, 23]. Glycemic control was not significantly different by age and sex but was significantly different by type of diabetes. $54 \%$ of type 1 diabetics had poor control compared to $24 \%$ in type 2 diabetics $(P<0.05)$. No study to date puts across scientific evidence for why type of diabetes affects long-term glycemic control.

Our results were from a pilot study which warrants further investigation and should be interpreted with caution. This is because all the samples were collected from one study centre and are not necessarily representative of the entire Zimbabwean population. The study was also not independent of some confounding variables such as effect of basal glucose levels which are naturally high in some people.

Studies to determine correlation between fasting glucose at a particular time and HbAlc levels should be carried out in the Zimbabwean population, in future. If a correlation is established, this can be used to estimate HbAlc levels in resource constrained settings. Similar studies have been done in other populations but may not be applicable to our population due to differences in diet and basal glucose levels $[9,14]$. Further studies to explain differences in long-term glycemic control among different types of diabetes should yield interesting results. This will provide better understanding and better interpretation of results and improve handling of diabetics depending on their type of diabetes.

\section{Conclusion}

In conclusion and according to the data obtained, $27 \%$ of type 1 and 2 diabetics had elevated plasma HbAlc levels representing poor long-term glycemic control. This may be an indication of poor adherence to both dietary and medicinal therapy and can predispose patients to developing long-term complications of diabetes mellitus. Regular HbAlc measurements at Public Diabetic Clinics should be done and results should be used to counsel and closely monitor patients with continuously elevated HbAlc.

\section{Conflict of Interests}

The authors declare that there is no conflict of interests regarding the publication of this paper.

\section{Acknowledgments}

The authors would like to thank the University of Zimbabwe, College of Health Sciences, Department of Medical Laboratory Sciences for funding the research; Department of Medical Laboratory Sciences Technical and Academic staff and fellow students for assistance and guidance during the practical work; Parirenyatwa Diabetic Clinic Staff and Patients; University of Zimbabwe, College of Health Sciences, Department of Community Medicine lecturers for assistance with statistics.

\section{References}

[1] C. A. Buritis, E. R. Ashwood, D. E. Bruns et al., Tietz Fundamentals of Clinical Chemistry, Saunders Elsevier's Publishers, St. Louis, Mo, USA, 6th edition, 2008.

[2] L. G. Whitby, I. W. Percy-Robb, and A. F. Smith, Lecture Notes on Clinical Chemistry, Blackwell Scientific Publications, London, UK, 3rd edition, 1984.

[3] G. Danaei, M. M. Finucane, Y. Lu et al., "National, regional, and global trends in fasting plasma glucose and diabetes prevalence since 1980: systematic analysis of health examination surveys and epidemiological studies with 370 country-years and $2 \cdot 7$ 
million participants," The Lancet, vol. 378, no. 9785, pp. 31-40, 2011.

[4] J. E. Shaw, R. A. Sicree, and P. Z. Zimmet, "Global estimates of the prevalence of diabetes for 2010 and 2030," Diabetes Research and Clinical Practice, vol. 87, no. 1, pp. 4-14, 2010.

[5] A. F. Amos, D. J. McCarty, and P. Zimmet, "The rising global burden of diabetes and its complications: estimates and projections to the year 2010," Diabetic Medicine, vol. 14, no. 12, pp. 8185, 1997.

[6] E. Sobngwi, F. Mauvais-Jarvis, P. Vexiau, J. C. Mbanya, and J. F. Gautier, "Diabetes in Africans. Part 1: epidemiology and clinical specificities," Diabetes and Metabolism, vol. 27, no. 6, pp. 628634, 2001.

[7] W. H. Mosley, J. L. Bobadilla, and D. T. Jamison, "The health transition: implications for health policy in developing countries," Disease Control Priorities in Developing Countries, vol. 23, pp. 673-699, 1993.

[8] E. Williams, "Clinical practice recommendations, standards of medical care for patients with diabetes mellitus," Diabetes Care, vol. 21, pp. 523-531, 2008.

[9] K. Sikaris, "The correlation of hemoglobin Alc to blood glucose," Journal of diabetes science and technology, vol. 3, no. 3, pp. 429-438, 2009.

[10] "Executive summary: Standards of Medical Care in Diabetes," Diabetes Care, vol. 32, pp. S6-s12, 2012.

[11] World Health Organisation, Use of Glycated Haemoglobin (HbAlc) in the Diagnosis of Diabetes Mellitus, World Health Organisation Publication, 2011.

[12] L. N. Pani, L. Korenda, J. B. Meigs et al., "Effect of aging on A1C levels in individuals without diabetes: evidence from the Framingham Offspring Study and the National Health and Nutrition Examination Survey 2001-2004," Diabetes Care, vol. 31, pp. 1991-1996, 2008.

[13] M. L. Larsen, M. Horder, and E. F. Mogensen, "Effect of longterm monitoring of glycosylated hemoglobin levels in insulindependent diabetes mellitus," New England Journal of Medicine, vol. 323, no. 15, pp. 1021-1025, 1990.

[14] American Diabetes Association, "Standards of medical care in diabetes," Diabetes Care, vol. 35, supplement 1, pp. S11-S63, 2012.

[15] J. M. Stollar, S. Dazhong, D. Conaway et al., "Importance of measuring glycosylated haemoglobin in ptients with myocardial infarction and known diabetes," American Journal of Cardiology, vol. 105, pp. 222-229, 2008.

[16] State of Alaska Epidemiology, "Diabetes management: glycated hemoglobin testing (HbAlc)," State of Alaska Epidemiology Bulletin, no. 18, 1998.

[17] J. Nicholas, J. Charlton, A. Dregan, and M. C. Gulliford, "Recent $\mathrm{HbAlc}$ values and mortality risk in type 2 diabetes. PopulationBased Case-Control Study," PLoS ONE, 2013.

[18] H. C. Gerstein, K. Swedberg, J. Carlsson et al., "The hemoglobin A1c level as a progressive risk factor for cardiovascular death, hospitalization for heart failure, or death in patients with chronic heart failure: an analysis of the candesartan in heart failure: Assessment of reduction in mortality and morbidity (CHARM) program," Archives of Internal Medicine, vol. 168, no. 15, pp. 1699-1704, 2008.

[19] G. F. Lewis, A. Carpentier, K. Adeli, and A. Giacca, "Disordered fat storage and mobilization in the pathogenesis of insulin resistance and type 2 diabetes," Endocrine Reviews, vol. 23, no. 2, pp. 201-229, 2002.
[20] K.-T. Khaw, N. Wareham, S. Bingham, R. Luben, A. Welch, and N. Day, "Preliminary communication: glycated hemoglobin, diabetes, and incident colorectal cancer in men and women: a prospective analysis from the European Prospective Investigation into Cancer-Norfolk Study," Cancer Epidemiology Biomarkers and Prevention, vol. 13, no. 6, pp. 915-919, 2004.

[21] E. Gakidou, L. Mallinger, J. Abbott-Klafter et al., "Management of diabetes and associated cardiovascular risk factors in seven countries: a comparison of data from national health examination surveys," Bulletin of the World Health Organization, vol. 89, no. 3, pp. 172-183, 2011.

[22] K. L. Ong, B. M. Y. Cheung, L. Y. F. Wong, N. M. S. Wat, K. C. B. Tan, and K. S. L. Lam, "Prevalence, treatment, and control of diagnosed diabetes in the U.S. National Health and Nutrition Examination Survey 1999-2004," Annals of Epidemiology, vol. 18, no. 3, pp. 222-229, 2008.

[23] J. M. Stollar, S. Dazhong, D. Conaway et al., "Importance of measuring glycosylated haemoglobin in ptients with myocardial infarction and known diabetes," American Journal of Cardiology, vol. 105, pp. 222-229, 2008. 

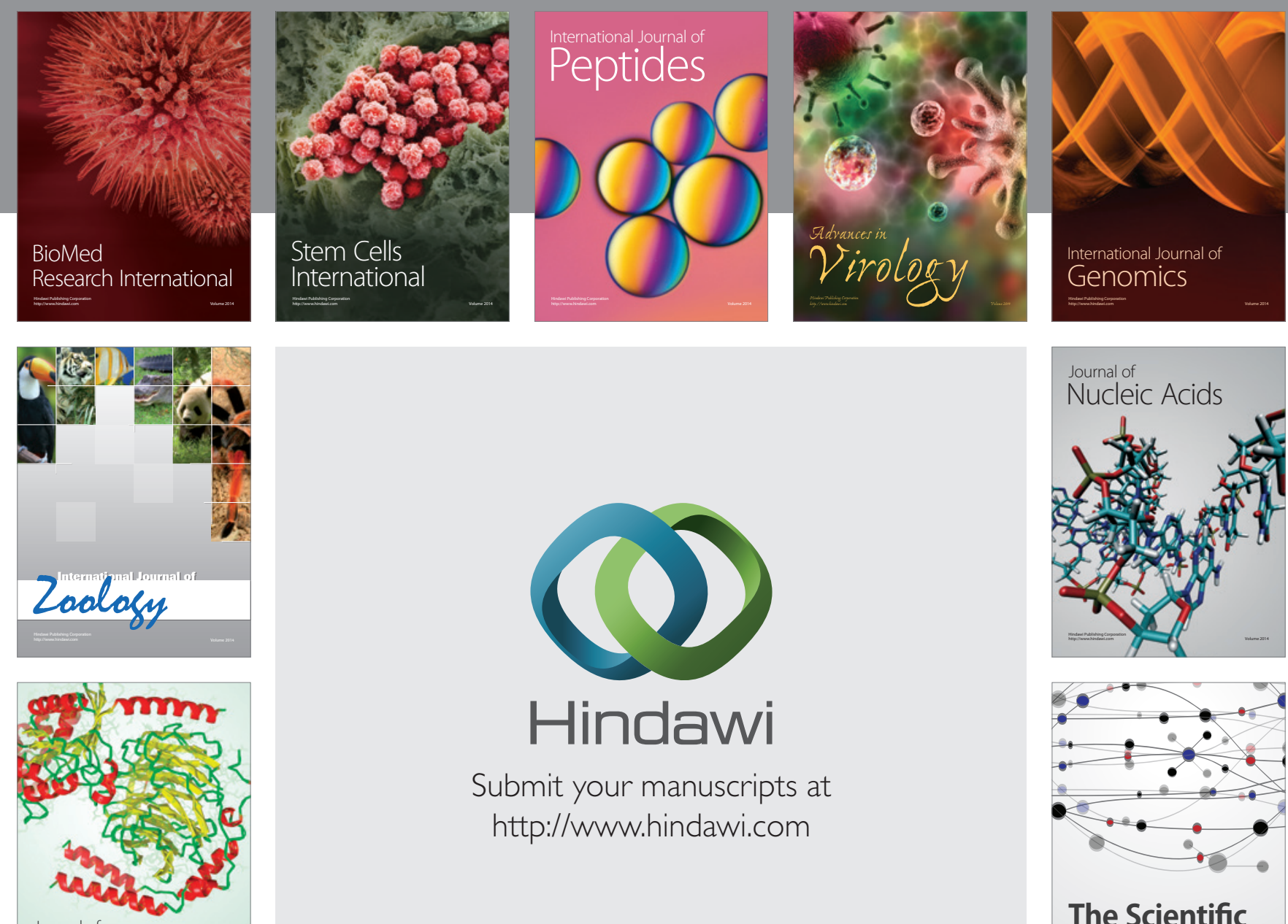

Submit your manuscripts at

http://www.hindawi.com

Journal of
Signal Transduction
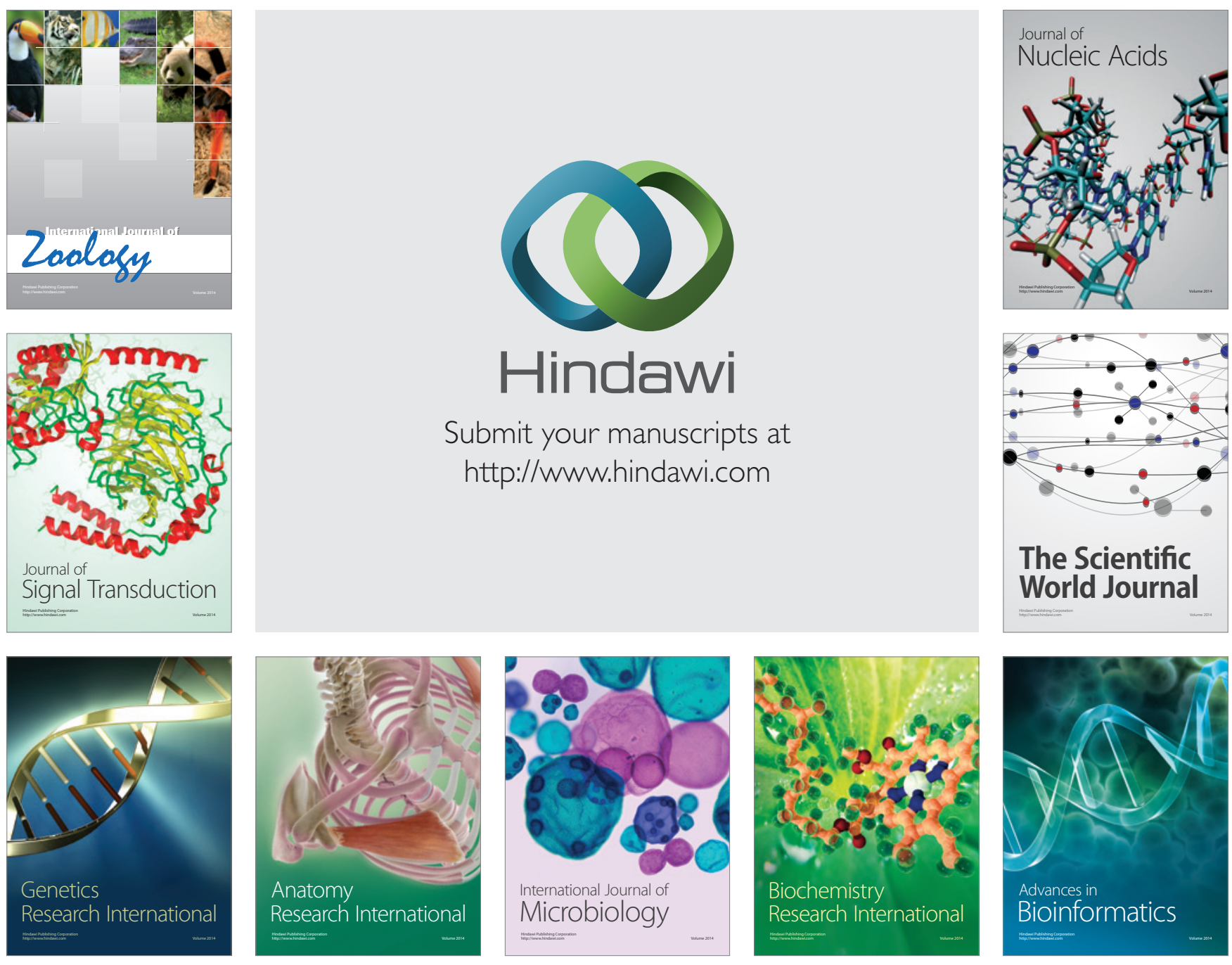

The Scientific World Journal
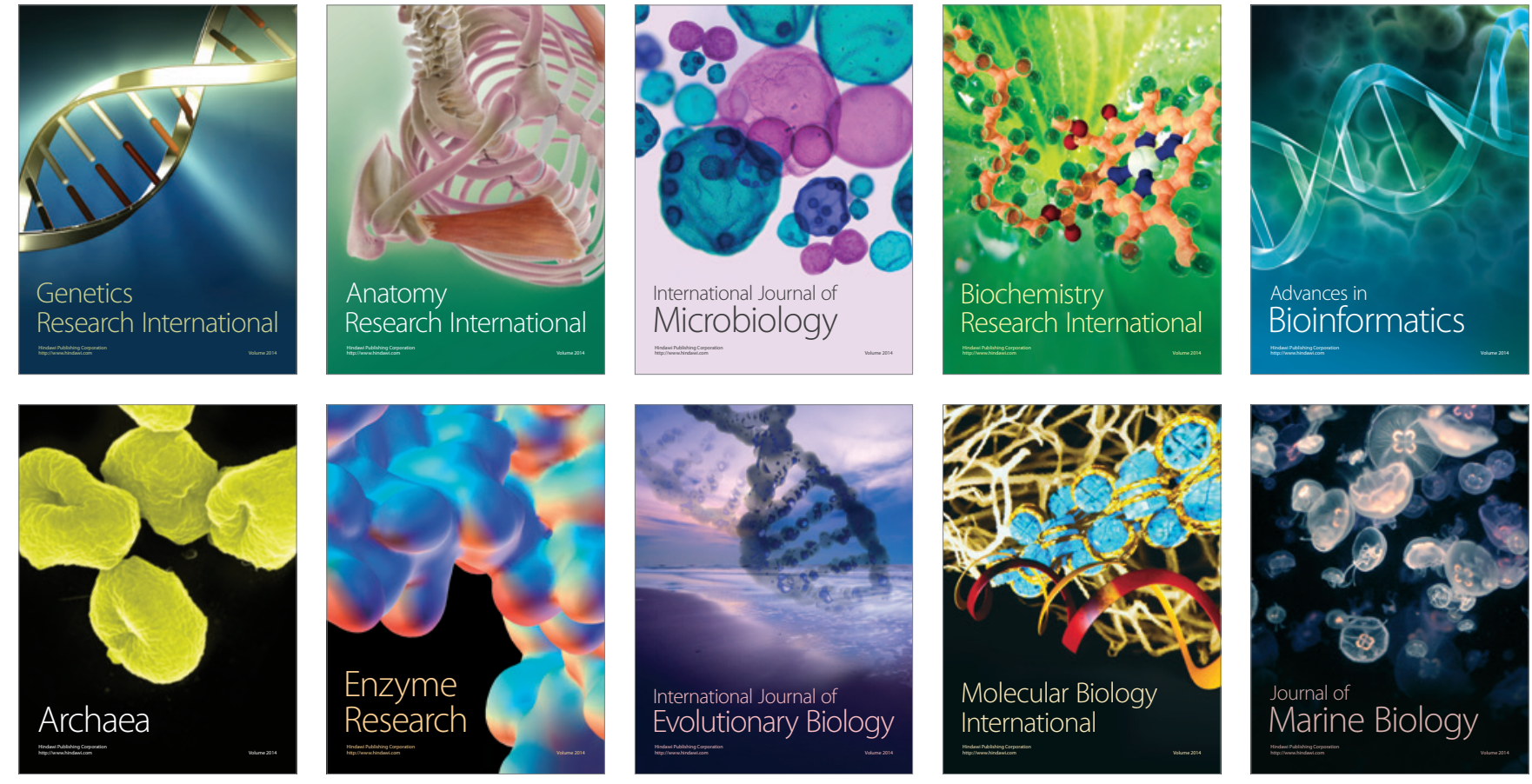